\title{
Body fat percentage assessment by skinfold equation, bioimpedance and densitometry in older adults
}

\author{
Erika Aparecida Silveira ${ }^{1 *}$, Larissa Silva Barbosa ${ }^{1}$, Ana Paula Santos Rodrigues ${ }^{1}$, Matias Noll $^{1,2}$ id and \\ Cesar De Oliveira ${ }^{3}$ (I)
}

\begin{abstract}
Background: Body fat estimation allows measuring changes over time attributed to interventions and treatments in different settings such as hospitals, clinical practice, nursing homes and research. However, only few studies have compared different body fat estimation methods in older adults with inconsistent results. We estimated body fat percentage (\%BF) and the level of agreement among dual energy $X$-ray absorptiometry (DXA), bioelectrical impedance (BIA) and Durnin \& Womersley's skinfold eq. (SF) in older Brazilian adults aged 60 years and older from the Elderly Project Goiânia, Brazil.
\end{abstract}

Methods: The analytical sample comprised of 132 participants who had DXA data. The level of agreement for the \%BF estimated by BIA, SF and DXA i.e. reference method, was examined using Bland and Altman's and Lin's plot.

Results: Overall, women had higher body mass index and \%BF values measured by all three methods used. BIA and SF equation showed strong concordance to estimate body fat percentage in all participants (CCC $=0.857$ and 0.861 , respectively) and among women (CCC $=0.788$ and 0.726 , respectively) when compared to DXA. However, both methods underestimated body fat percentage in women and men with high body fat percentage. A strong level of agreement was observed between DXA and the anthropometric equation developed by Durnin \& Womersley in men $(C C C=0.846)$, while BIA had a moderate concordance $(C C C=0.505)$ in this group.

Conclusion: The examined methods indicated different body fat estimates. However, the best agreement was observed between DXA and the anthropometric SF equation for men. Future research in older adults should develop new SF equations considering different ethnic groups.

Keywords: Body composition, Adiposity, Anthropometry, Aging, Bioelectrical impedance, Dual energy X-ray absorptiometry

\section{Background}

The prevalence of obesity has considerably increased worldwide over the last few decades and is a growing concern among older adults [1]. Obesity has been linked to hypertension, dyslipidemia, insulin resistance and

\footnotetext{
* Correspondence: erikasil@terra.com.br

${ }^{1}$ Faculty of Medicine, Health Science Post-Graduation Program, Universidade Federal de Goiás, Goiânia, Brazil

Full list of author information is available at the end of the article
}

diabetes mellitus, which can lead to cardiovascular diseases such as coronary heart disease and ischemic stroke [2-4]. The most widely method used to assess the prevalence of obesity status in population studies is the body mass index (BMI) [1]. However, limitations and controversies about the use of BMI have been highlighted especially due to its underestimation of obesity prevalence. Body composition has been considered a better alternative to BMI in older adults due to age-related increases 
in body fat percentage (\%BF) $[5,6]$. High body fat is associated with increased mortality [7] and unsuccessful ageing [8]. Therefore, \%BF estimation is essential in epidemiological studies and in health services routine instead of relying only on BMI.

Skinfold (SF) measurements allow the assessment of body composition due to the strong relationship between the amount of subcutaneous fat and total BF [9, 10]. SF is a non-invasive method, easy to be measured and has low operating costs [10]. However, there is still a need to evaluate SF equations' accuracy and agreement to predict \%BF in older adults $[11,12]$.

The development of methods and/or equations for body composition estimation in older adults that can be used in population surveys while accounting for the agerelated changes in body composition remains a major challenge [11, 13-15]. Aging affects the subcutaneous and visceral fat distribution. Thus, it is important to use methods such as bioelectrical impedance (BIA) and dual-energy X-ray absorptiometry (DXA) to analyze the whole body. DXA is the reference standard method for body composition estimation, particularly in older adults, as it directly measures muscle mass, adipose tissue and bone density with both good precision and accuracy $[6,16,17]$. However, its high cost and limited device availability make this method unfeasible in population studies and clinical settings.

Body fat estimation is very important later in life $[7,8,11,16,18,19]$. It improves chronic conditions diagnosis and mortality risk assessment. In addition, body fat estimation allows measuring changes over time attributed to interventions and treatments in different settings such as hospitals, clinical practice, nursing homes and research. However, only few studies $[11,20-24]$ have compared different body fat estimation methods in older adults with inconsistent results. Therefore, we aimed to evaluate the agreement of BIA and SF equation with DXA, as the reference method, to estimate the BF percentage in older Brazilian adults.

\section{Methods}

\section{Study design and participants}

Analyses for this study used data from the Elderly Project Goiânia [2, 18, 25-27], which aims to evaluate the health and nutritional status in older adults aged 60 years and older. It is a cohort study with multistage sampling of non-institutionalized older adults in Goiânia city, capital of the Goiás state, Brazil. The initial cohort sample comprised of 418 older adults selected through a probabilistic sampling. For the present study, only a subsample of 132 participants were randomly selected ensuring the same proportion of age distribution, neighborhood and BMI ranges observed in the initial sample, for further assessments including DXA, BIA and skinfold measurement. The number of participants in the subsample was determined based on the Bland and Altman method [10, 28]. We excluded participants who were institutionalized, had incapacitating diseases that did not permit them from leaving their bed or those with partial or total amputation. Individuals with pacemakers or any type of metal adjacent to their body, which was a contra-indication for BIA and DXA examination, and those who were unable to respond to the questionnaire, for reasons such as severe deafness or muteness, were also excluded. A detailed description of the study can be found elsewhere [2, 18, 25-27].

Selected participants were contacted via telephone and were informed about the aim and procedures to be followed during the data collection stage. They were also advised about the preparation required prior to BIA and DXA assessments. All evaluations were performed on the same day during the morning. In order to minimize errors in body composition assessment by the BIA method, participants were given the following instructions: absolute fasting for at least $4 \mathrm{~h}$ before the exams; no exercise within the $12 \mathrm{~h}$ before the test; urinate $30 \mathrm{~min}$ before the test; no consumption of alcohol and foods containing caffeine within $24 \mathrm{~h}$ prior to the test and no diuretic use within $24 \mathrm{~h}$ prior to the test.

\section{Study variables}

The following anthropometric measures were collected: weight, height, bicipital, tricipital, subscapular and supra-iliac SFs, BIA and DXA. Trained interviewers conducted a standardized and pre-tested survey. SF anatomical points measured were identified by the procedures described by Lohman, Roche and Martorell [29]. In order to improve all anthropometric measures (SF, weight, height), to ensure greater accuracy and validated it, we performed training to standardize the techniques between researcher who collect those data [30].

Weight was measured using the digital Tanita electronic scale that has a capacity of $150 \mathrm{~kg}$ and a precision of $100 \mathrm{~g}$. Height was measured using an inelastic and inextensible tape, with a length, width, and precision of $2.00 \mathrm{~m}, 2 \mathrm{~cm}$ and $0.1 \mathrm{~cm}$, respectively, along with a set square. The measurements were conducted according to the techniques described by Gordon et al. [29]. The BMI value was obtained using these measurements. During the anthropometric measures, participants wore only light or intimate clothes, no shoes and no objects in their pockets, on their hands or on their head. 
The SF measurements i.e. bicipital, tricipital, subscapular and supra iliac were performed with a Lange adipometer, with a constant pressure of $10 \mathrm{~g} / \mathrm{mm}^{2}$ on the contact surface and accuracy of $1 \mathrm{~mm}$, with a $0-65 \mathrm{~mm}$ scale. The different sites' measurements were successively performed, and the final values were obtained as the average of three measurements. The SFs were measured according to the recommendations by Harrison et al. [29].

Body density values were calculated using the older adults-specific equation of Durnin and Womersley $[10,31]$ :

$$
\begin{aligned}
& \text { Men }: \mathrm{D}\left(\mathrm{g} / \mathrm{cm}^{3}\right)=1.1765-0.0744 \log _{10}(\Sigma 4 \mathrm{SF}) \\
& \text { Women }: \mathrm{D}\left(\mathrm{g} / \mathrm{cm}^{3}\right)=1.1339-0.0645 \log _{10}(\Sigma 4 \mathrm{SF})
\end{aligned}
$$

The body density equations were converted into fat percentage, by using the Siri equation: $\% \mathrm{BF}=((4.95 /$ D) -4.50$) \times 100$, for the purpose of the analysis. Body density conversion is needed as the criterion measure. Siri equation [32] establishes constants of fat mass and fat free mass.

Body fat percentage was also measured using BIA with the Maltron BF906 device, with an impedance of $200-1000 \Omega$, precision of $\pm 4 \Omega$, and a frequency of 50 $\mathrm{kHz}$. The measurement was performed with the participant lying in the supine position. An emitter electrode was placed adjacent to the metacarpal-phalangeal joint of the dorsal surface of the right hand, and the other distally of the transverse arch of the upper surface of the right foot. One detector electrode was placed between the radius and ulna distal prominences of the right wrist, whereas the other electrode was placed between the medial and lateral malleoli of the right ankle. Measurement of the \%BF by DXA was obtained through a full body scan using the Lunar DPX-MD PLUS device and software version 7.52.002 DPX-L, calibrated daily. Participants lied down on a table in the supine position and remained immobile during the scan. Individuals wore only an apron, and were barefoot, without any earrings, rings, dental prostheses, or other metallic materials.

Database was established using EPIDATA version 3.1 with double input for consistency checking. All the analyses were performed using STATA version 12.0. Shapiro-Wilk test was used to analyze normality of the distribution. Student's t-test was used to compare \%BF average values between men and women. Concordance between the \%BF measured by the Durnin and Womersley equation and BIA with the \%BF measured by DXA (standard reference), was assessed using the concordance correlation coefficient (CCC) or Lin plots proposed by Bland and Altman [28, 33, 34]. CCC combines precision and accuracy to establish whether the observations deviate significantly from the line of perfect concordance $\left(45^{\circ}\right)$. A value of one corresponds to the regression line lying exactly on the line of perfect concordance [33]. The following cut-off points were adopted: negligible concordance $\quad(\mathrm{CCC}=0.00-0.10)$; weak concordance $(\mathrm{CCC}=0.10-0.39)$; moderate concordance $(\mathrm{CCC}=0.40$ $0.69)$; strong concordance $(\mathrm{CCC}=0.70-0.89)$ and very strong concordance $(\mathrm{CCC}=0.90-1.00)$ [35].

Bland and Altman's protocol includes the plotting of a concordance graph (average versus difference), and the calculation of the limit of concordance [28, 34]. This technique allows the visual assessment of the concordance and of the $95 \%$ concordance limit.

\section{Ethics approval and informed consent}

This study was conducted according to the guidelines laid down in the Declaration of Helsinki. All participants gave written informed consent. The Research Ethics Committee has approved the Elderly Project Goiânia (number: 031/2007).

\section{Results}

DXA and BIA were performed in 132 participants from the initial cohort. All the variables included in this analysis were normally distributed. Women exhibited higher \%BF values in all the methods used $(p<0.001)$ (Table 1).

The dispersion of \%BF values estimated by BIA and SF equation compared to DXA values are displayed in Figs. 1 to 3 . The concordance correlation coefficient analysis showed a strong concordance between BIA and SF equation for all participants and among women (Figs. 1 and 2), whereas a moderate concordance (0.51) was observed for BIA in men (Fig. 3). The higher concordance in our analyses $(0.85$ - strong concordance) was observed for \%BF evaluated by SF equation in men (Fig. 3), followed by BIA in women (0.79 - strong concordance) (Fig. 2).

The analysis of the regression line slope for all participants and between men and women based on the Lin plots showed that an underestimation of \%BF by BIA occurs for all levels of BF. However, this underestimation increases at high levels, mainly after $40 \%$, when using SF equation (Figs. 2 and 3).

The graphical approach of Bland and Altman showed that BIA and SF equation tend to underestimate the $\% \mathrm{BF}$ values in both genders with wide limits of concordance. The underestimation of \%BF by BIA in men was 9.5 and $3.5 \%$ in women, while for SF equation for both groups was around 2.3 and $2.8 \%$, respectively. Overall, BIA had higher values of underestimation compared to SF equation (Figs. 2 and 3). 
Table 1 Age and different body composition measures distribution by gender

\begin{tabular}{|c|c|c|c|c|c|}
\hline \multirow[t]{2}{*}{ Variables } & \multicolumn{2}{|l|}{ Male $(n=52)$} & \multicolumn{2}{|c|}{ Female $(n=80)$} & \multirow{2}{*}{$\begin{array}{l}\text { Value } \\
p\end{array}$} \\
\hline & Mean \pm SD & Range & Mean \pm SD & Range & \\
\hline Age (years) & $70.50 \pm 6.68$ & $60.00-91.00$ & $69.69 \pm 6.23$ & $60.00-86.00$ & 0.642 \\
\hline BMI $\left(\mathrm{kg} / \mathrm{m}^{2}\right)^{1}$ & $25.75 \pm 4.05$ & $14.42-35.36$ & $27.37 \pm 5.75$ & $13.67-40.02$ & 0.093 \\
\hline \%BF D\&W equation ${ }^{2}$ & $27.88 \pm 6.75$ & 8.09-39.68 & $39.99 \pm 5.22$ & $18.38-50.03$ & $0.0001^{*}$ \\
\hline$\% B F B I A^{3}$ & $27.90 \pm 7.00$ & $3.10-38.90$ & $39.28 \pm 8.66$ & $13.80-55.00$ & $0.0001^{*}$ \\
\hline$\% B F D X A^{4}$ & $30.21 \pm 8.63$ & $5.40-47.40$ & $42.82 \pm 9.00$ & $11.20-57.10$ & $0.0001^{*}$ \\
\hline
\end{tabular}

${ }^{1}$ Body mass index; ${ }^{2}$ Body fat percentage estimated with the SF equation of Durnin \& Womersley; ${ }^{3}$ Body fat percentage estimated with bioelectrical impedance (BIA); ${ }^{4}$ Body fat percentage estimated using dual energy X-ray absorptiometry (DXA); ${ }^{*}$ Significant differences between sexes

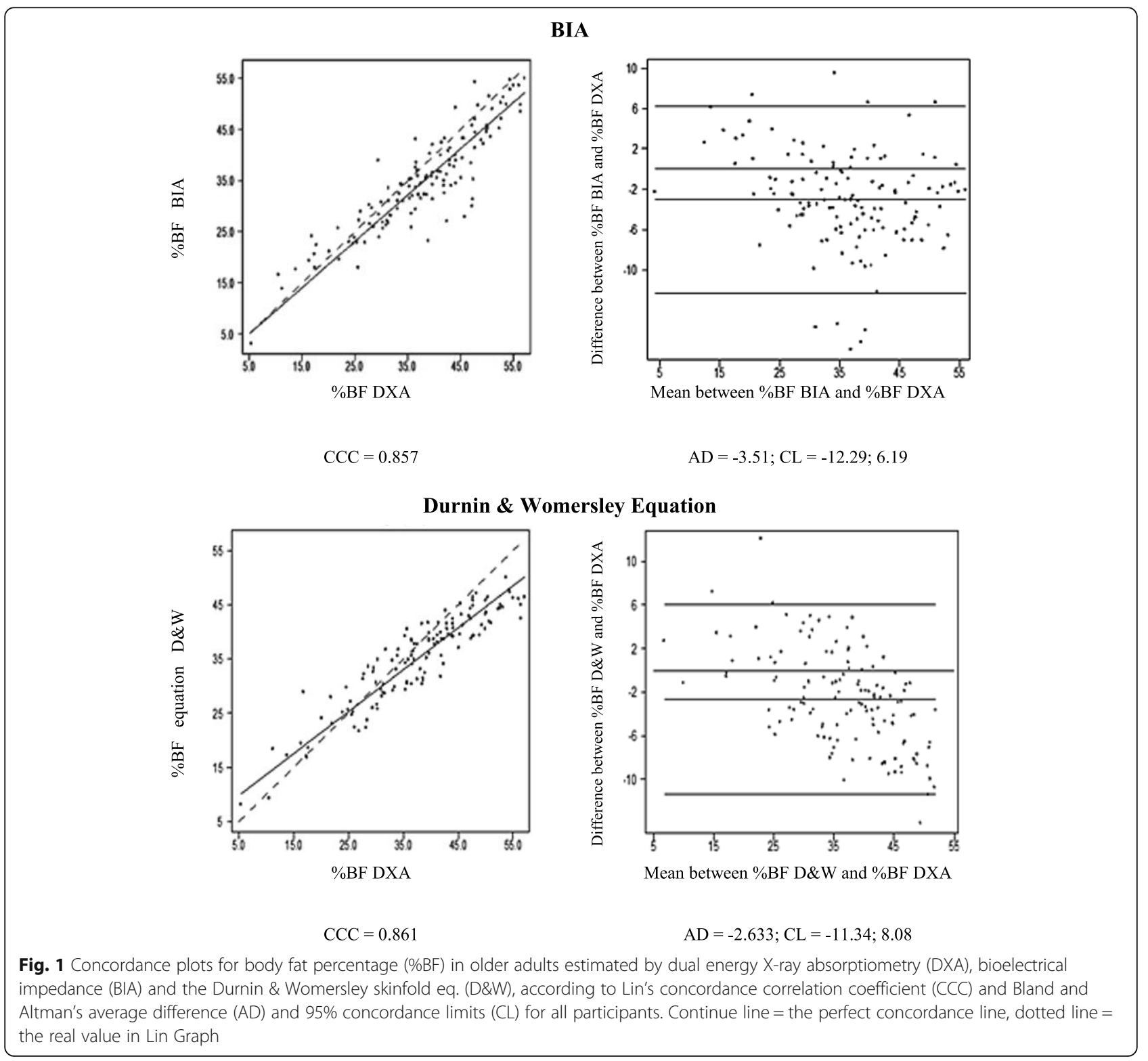




\section{BIA}

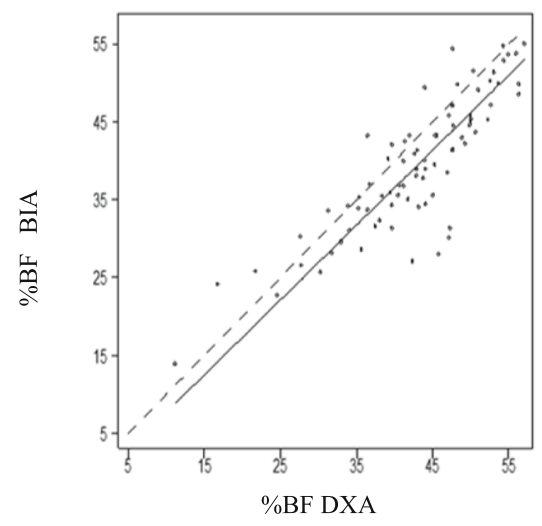

$\mathrm{CCC}=0.788$

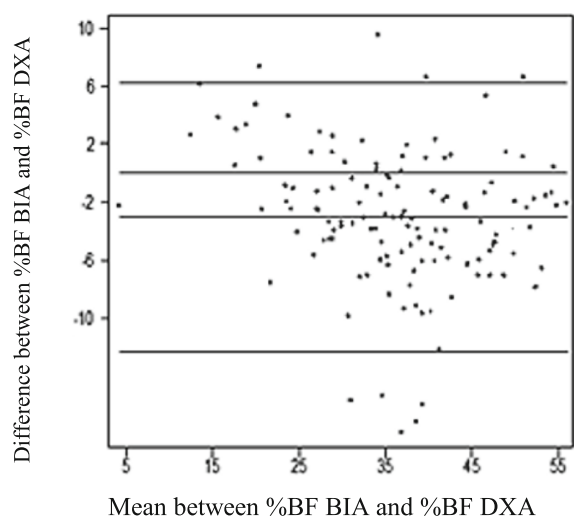

$\mathrm{AD}=-3.534 ; \mathrm{CL}=-12.95 ; 5.88$

Durnin \& Womersley Equation

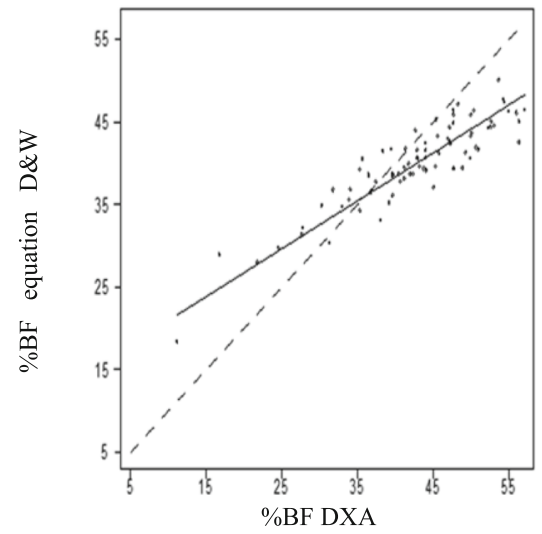

$\mathrm{CCC}=0.726$

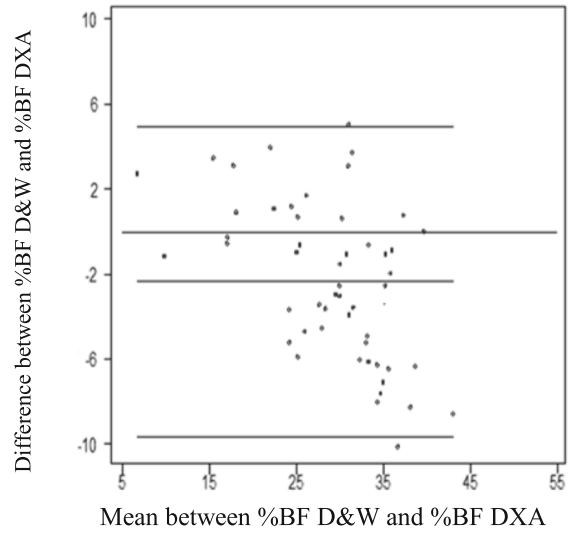

$\mathrm{AD}=-2.826 ; \mathrm{CL}=-12.37 ; 6.72$

Fig. 2 Concordance plots for body fat percentage $(\% \mathrm{BF})$ in women estimated by dual energy $\mathrm{X}$-ray absorptiometry (DXA), bioelectrical impedance (BIA), and the Durnin \& Womersley equation, according to Lin's concordance correlation coefficient (CCC) and Bland and Altman's average difference $(A D)$ and $95 \%$ concordance limits $(C L)$. Continue line $=$ the perfect concordance line, dotted line $=$ the real value in Lin Graph

\section{Discussion}

In the present study, our main findings showed that values obtained through both methods i.e. BIA and $\mathrm{SF}$ equation underestimated \%BF in all participants and between men and women. This underestimation increased in the higher values of \%BF, mainly after $40 \%$ for the SF equation. However, the CCC that measured accuracy and precision between the three methods investigated in the present study was more than 0.85 for all participants. This value decreased in women (0.72) but remained in the strong concordance range. On the other hand, among men, BIA assessment provided the worst level of agreement i.e. moderate $(\mathrm{CCC}=0.5)$, with an underestimated average of $9.5 \%$ and had a large limit of agreement. Previous research comparing BIA and SF equations against DXA showed inconsistent findings in older adults related to sex and age-related changes in hydration and bone content and mineralization [15, 21, 24]. When comparing results based on different evaluation methods, it is fundamental to establish whether the measures are either underestimating or overestimating in relation to others [36, 37].

This study represents an important contribution to the literature comparing different methods to estimate \%BF in older adults since there are few studies [11, 20] addressing the same aim of our study. At present, there is only another study in older adults [11], aged 65 years and older, and the other studies were conducted in middle-aged adults. 


\section{BIA}
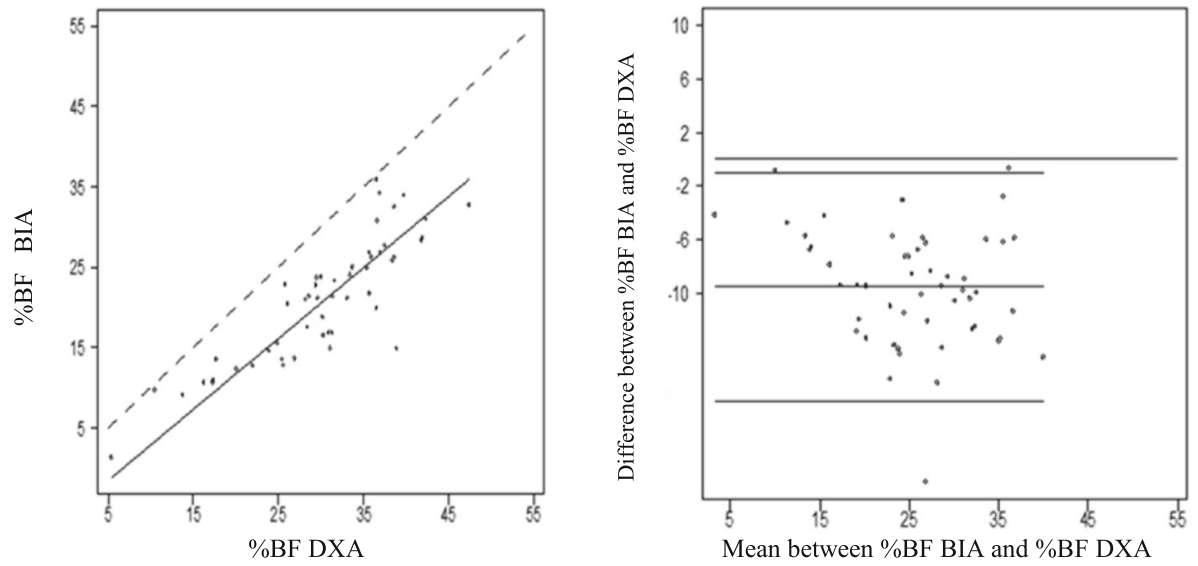

$\mathrm{CCC}=0.505$

$\mathrm{AD}=-9.504 ; \mathrm{CL}=-18.06 ;-0.94$

Durnin \& Womersley Equation

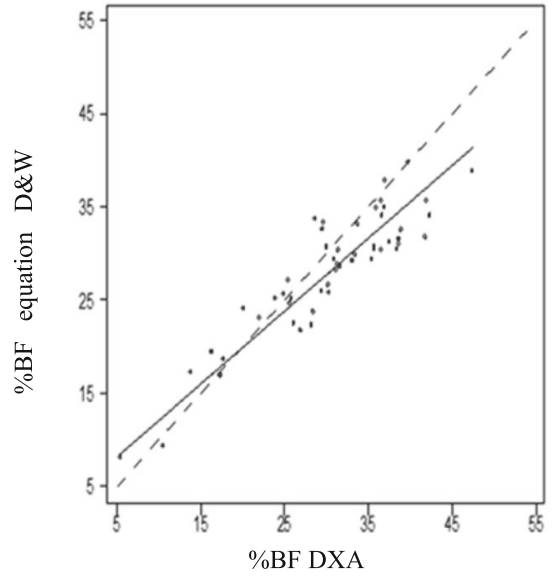

$\mathrm{CCC}=0.846$

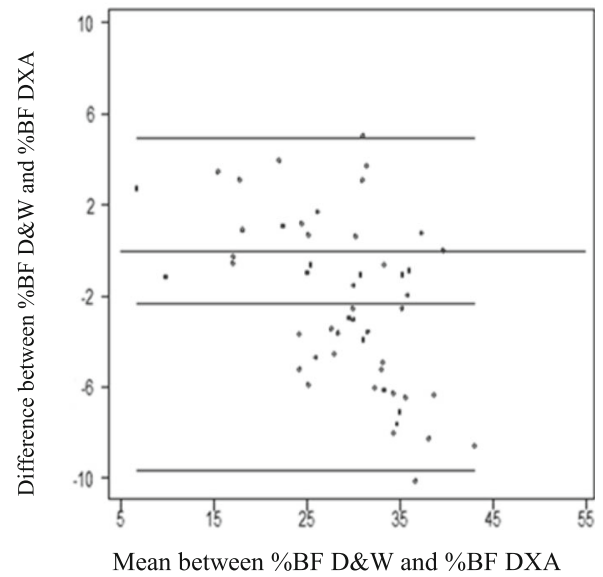

$\mathrm{AD}=-2.335 ; \mathrm{CL}=-9.61 ; 4.94$

Fig. 3 Concordance plots for body fat percentage (\%BF) in men estimated by dual energy X-ray absorptiometry (DXA), bioelectrical impedance (BIA), and the Durnin \& Womersley equation, according to Lin's concordance correlation coefficient (CCC) and Bland and Altman's average difference $(A D)$ and $95 \%$ concordance limits $(C L)$. Continue line $=$ the perfect concordance line, dotted line $=$ the real value in Lin Graph

The SF anthropometric equations [31] were based on the calculation of body density, assessed by submerged weight, in women aged $>50$ years. The two-compartment model (hydrostatic weighing), which divides the body into fat-free mass and fat mass, was used to develop this equation, and its use has been questioned in older adults. The fat redistribution, loss of compressibility of SFs and the BF and fat free mass constants, adopted by this method, do not reflect the specific characteristics of older adults, which can significantly affect the reliability of BF estimates [38]. Despite the criticism to this method, our results were quite positive and show strong accuracy of SF equation in both genders, mainly in men.
BIA has been recommended as an alternative method to estimate body fat percentage, when DXA cannot be used, because of the high concordance between the two methods in middle-aged adults. This evaluation should be performed in individuals who are within the normal range of total body fat, since BIA tends to overestimate the $\% \mathrm{BF}$ in lean individuals and to underestimate the $\% \mathrm{BF}$ in obese individuals $[17,38]$. Our results are in agreement with previous studies on middle-aged individuals, wherein BIA underestimated the $\% \mathrm{BF}[17,39]$. The accuracy of the BIA Maltron BF906 equipment used in this study has been previously evaluated in Brazilians against a gold-standard method i.e. hydrostatic weighing 
showing a moderate concordance correlation $(r=0.70$ and $0.75, p=<0.01)[40,41]$. The Maltron BF906 was the best BIA equipment compared to other three models analyzed.

Our findings indicated differences in anthropometric and body composition measures between men and women which is consistent with previous studies [42, 43]. The \%BF, evaluated via DXA, BIA, and SF equation, in women was higher than that in men, coherent with that noted in previous studies [42, 43]. The SF thickness (subscapular, tricipital, bicipital, and supra-iliac) was also higher in women, which may be related to the larger distribution of subcutaneous fat in women [16]. We highlight that body composition analysis and the accuracy of methods should be stratified by gender especially in older adults.

Durnin and Womersly SF equation adopted in this study is one of the most used and accurate method to evaluate body fat $[10-12,31]$. Age, sex and obesity are important factors in terms of SFs and body density measures, since the same SF level at different ages may be associated with changes in the fat distribution pattern [31]. Despite in the present study the CCC for SF equation in both sexes shows strong agreement, it tend to underestimate $\% \mathrm{BF}$ of those with more than $40 \%$ of body fat and the concordance limit in Bland and Altman's graphic tend to underestimate. A previous study had demonstrated good agreement of Durnin and Womersly SF equation in estimating body fat of 78 nonobese and obese Caucasian older heathy adults [11] nonetheless it did not perform Lin's concordance correlation coefficient or Bland and Altman's analyses as we did. Hence, it is likely that the individuals with higher body fat percentage have high amount of internal fat that were not detected by SF measurements, which could have led to the underestimation by SF equation [31]. Due to the explanations above the SF equation is not accurate enough to be used in clinical settings in older adults with more than $40 \%$ of body fat.

The Bland and Altman approach [28] used in our analyses to estimate the average difference and concordance limits between two BF methods has also been used in previous studies [37], wherein it was stated that the use of correlation coefficients may not be appropriate, as a high correlation may not reflect a high level of concordance $[28,37]$. The average difference observed in our findings between the methods used and the reference standard indicated that some participants might exhibit considerable diagnostic errors when using either method, since the \%BF may be underestimated or overestimated depending on the method used.

In Brazil, the Ministry of Health considers an older adult those people aged 60 years and older while in North America and Europe an older adult is someone aged 65 years and older. This could have been a limitation of this study; however, the mean age of our participants was over 70 years and, therefore, this fact will not limit the comparison of our results with other studies. One possible limitation that could also be stated relates to the generalizability of the findings, due to our sample not being nationally representative. Another potential limitation of our study could be attributed to the fact that the SF assessment is very difficult especially in older adults. However, in order to minimize such errors, we adopted the following strategies: use of good quality skinfold caliper, all anthropometrics were extensively trained in volunteer older adults, measures were taken three times and we provided previous orientation about hydration status.

\section{Conclusions}

BIA and SF equation showed a strong level of concordance to estimate body fat percentage in all participants and among women when compared to our standard reference i.e. DXA. However, both methods underestimated body fat percentage in women and men with high body fat percentage. A strong level of concordance was observed between DXA and the anthropometric equation developed by Durnin and Womersley in men, while BIA had a moderate concordance in this group. Future research in older adults should consider various methods, different ethnic groups and the development of new SF equations.

\section{Acknowledgments \\ The authors would like to thank the FAPEG Foundation, the Study Group on Severe Obesity (GEOG) and the Instituto Federal Goiano for funding this study.}

\section{Authors' contributions}

The authors' contributions are as follows: E.A.S., L.S.B. and M.N. designed and conducted the research; E.A.S., L.S.B., A.P.S.R, M.N., and C.O. analyzed the data, interpreted the results, and wrote the paper. All authors read and approved the final paper. E.A.S. is the principal investigator of this research project Elderly Project Goiânia.

\section{Funding}

This study was supported by National Council for Scientific and Technological Development of Brazil (CNPq) (no. 14/2008 - Band B no. 480927/2208-1)

\section{Availability of data and materials \\ The datasets used and/or analysed during the current study are available from the corresponding author on request.}

Ethics approval and consent to participate

This study was conducted according to the guidelines laid down in the declaration of Helsinki. All participants gave written informed consent. The research ethics committee has approved the elderly project Goiânia (number: 031/2007)

Consent for publication

Not applicable.

Competing interests

The authors declare no conflict of interest. 


\section{Author details}

${ }^{1}$ Faculty of Medicine, Health Science Post-Graduation Program, Universidade Federal de Goiás, Goiânia, Brazil. ${ }^{2}$ Instituto Federal Goiano, Goiânia, Brazil. ${ }^{3}$ Department of Epidemiology \& Public Health, University College London, London, UK

Received: 3 April 2020 Accepted: 9 July 2020

Published online: 18 July 2020

\section{References}

1. NCD Risk Factor Collaboration (NCD-RisC) L, Abdeen ZA, Hamid ZA, AbuRmeileh NM, Acosta-Cazares B, Acuin C, et al. Worldwide trends in bodymass index, underweight, overweight, and obesity from 1975 to 2016: a pooled analysis of 2416 population-based measurement studies in 128.9 million children, adolescents, and adults. Lancet (London, Engl). Elsevier; 2017;390: 2627-2642. doi:https://doi.org/10.1016/S0140-6736(17)32129-3.

2. da Silveira EA, Vieira LL, Jardim TV, de Souza JD, da Silveira EA, Vieira LL, et al. Obesity and its association with food consumption, diabetes mellitus, and acute myocardial infarction in the elderly. Arq Bras Cardiol. 2016;107: 509-17. https://doi.org/10.5935/abc.20160182.

3. Echouffo-Tcheugui JB, Short MI, Xanthakis V, Field P, Sponholtz TR, Larson $M G$, et al. Natural history of obesity sub-phenotypes: dynamic changes over two decades and prognosis in the Framingham heart study. J Clin Endocrinol Metab. 2018. https://doi.org/10.1210/jc.2018-01321.

4. Hubert HB, Feinleib M, McNamara PM, Castelli WP. Obesity as an independent risk factor for cardiovascular disease: a 26-year follow-up of participants in the Framingham heart study. Circulation. 1983;67:968-77 Available: http://www.ncbi.nlm.nih.gov/pubmed/6219830.

5. Reilly JJ, El-Hamdouchi A, Diouf A, Monyeki A, Somda SA. Determining the worldwide prevalence of obesity. Lancet. 2018:391:1773-4. https://doi.org/ 10.1016/S0140-6736(18)30794-3.

6. Okorodudu DO, Jumean MF, Montori VM, Romero-Corral A, Somers VK, Erwin PJ, et al. Diagnostic performance of body mass index to identify obesity as defined by body adiposity: a systematic review and metaanalysis. Int J Obes. 2010;34:791-9. https://doi.org/10.1038/ijo.2010.5

7. Padwal R, Leslie WD, Lix LM, Majumdar SR. Relationship among body fat percentage, body mass index, and all-cause mortality. Ann Intern Med. 2016;164:532. https://doi.org/10.7326/M15-1181.

8. Tyrovolas S, Haro J-M, Mariolis A, Piscopo S, Valacchi G, Bountziouka V, et al. Skeletal muscle mass and body fat in relation to successful ageing of older adults: the multi-national MEDIS study. Arch Gerontol Geriatr. 2016;66:95101. https://doi.org/10.1016/j.archger.2016.04.017.

9. González-Ruíz K, Medrano M, Correa-Bautista J, García-Hermoso A, PrietoBenavides D, Tordecilla-Sanders A, et al. Comparison of bioelectrical impedance analysis, slaughter skinfold-thickness equations, and dual-energy X-ray absorptiometry for estimating body fat percentage in Colombian children and adolescents with excess of adiposity. Nutrients. 2018;10:1086. https://doi.org/10.3390/nu10081086.

10. Hillier SE, Beck L, Petropoulou A, Clegg ME. A comparison of body composition measurement techniques. J Hum Nutr Diet. 2014;27:626-31. https://doi.org/10.1111/jhn.12197.

11. Chambers AJ, Parise E, Mccrory JL, Cham R. A comparison of prediction equations for the estimation of body fat percentage in non-obese and obese older Caucasian adults in the United States. J Nutr Health Aging. 2014;18:586-90. https://doi.org/10.1007/s12603-014-0017-3.

12. Bacchi E, Cavedon V, Zancanaro C, Moghetti P, Milanese C. Comparison between dual-energy $\mathrm{X}$-ray absorptiometry and skinfold thickness in assessing body fat in overweigh/obese adult patients with type-2 diabetes. Sci Rep Nat Publ Group. 2017;7:17424. https://doi.org/10.1038/s41598-01717788-y.

13. Perissinotto E, Pisent C, Sergi G, Grigoletto F. ILSA working group (Italian longitudinal study on ageing). Anthropometric measurements in the elderly: age and gender differences. Br J Nutr. 2002;87:177-86 Available: http:// www.ncbi.nlm.nih.gov/pubmed/11895170

14. Silveira EA, Kac G, Barbosa LS. Obesity prevalence and associated factors in the elderly in Pelotas, Rio Grande do Sul state, Brazil: obesity classifi cation according to two cutoff points for body mass index. Cad Saude Publica. 2009;25:1569-77. https://doi.org/10.1590/S0102-311X2009000700015.

15. Gupta N, Balasekaran G, Victor Govindaswamy V, Hwa CY, Shun LM. Comparison of body composition with bioelectric impedance (BIA) and dual energy X-ray absorptiometry (DEXA) among Singapore Chinese. J Sci Med Sport. 2011;14:33-5. https://doi.org/10.1016/j.jsams.2010.04.005.

16. Henche SA, Torres RR, Pellico LG. An evaluation of patterns of change in total and regional body fat mass in healthy Spanish subjects using dualenergy X-ray absorptiometry (DXA). Eur J Clin Nutr. 2008;62:1440-8. https:// doi.org/10.1038/sj.ejcn.1602883.

17. Ling CHY, de Craen AJM, Slagboom PE, Gunn DA, Stokkel MPM, Westendorp RGJ, et al. Accuracy of direct segmental multi-frequency bioimpedance analysis in the assessment of total body and segmental body composition in middle-aged adult population. Clin Nutr. 2011;30:610-5. https://doi.org/10.1016/j.clnu.2011.04.001.

18. Silveira EA, Ferreira CCDC, Pagotto V, Santos ASEADC, VelasquezMelendez G. Total and central obesity in elderly associated with a marker of undernutrition in early life - sitting height-to-stature ratio: A nutritional paradox. Am J Hum Biol. 2017;29:e22977. https://doi.org/10. 1002/ajhb.22977.

19. Forte R, Pesce C, de Vito G, Boreham CAG. The body fat-cognition relationship in healthy older individuals: does gynoid vs android distribution matter? J Nutr Health Aging. 2017:21:284-92. https://doi.org/10.1007/ s12603-016-0783-1.

20. Thiebaud RS, Abe T, Loenneke JP, Fujita E, Akamine T. Body fat percentage assessment by ultrasound subcutaneous fat thickness measurements in middle-aged and older adults. Clin Nutr Elsevier; 2018;0. doi:https://doi.org/ 10.1016/j.clnu.2018.11.017

21. Clasey JL, Kanaley JA, Wideman L, Heymsfield SB, Teates CD, Gutgesell ME, et al. Regarding the validity of methods of body composition assessment in young and older men and women (multiple letters). J Appl Physiol. 2000;89: 2518-20. https://doi.org/10.1152/jappl.2000.89.6.2518.

22. Gallagher D, Heymsfield SB, Heo M, Jebb SA, Murgatroyd PR, Sakamoto Y. Healthy percentage body fat ranges: an approach for developing guidelines based on body mass index. Am J Clin Nutr. 2000;72:694-701. https://doi. org/10.1093/ajcn/72.3.694.

23. Goran MI, Toth MJ, Poehlman ET. Assessment of research-based body composition techniques in healthy elderly men and women using the 4compartment model as a criterion method. Int J Obes. 1998;22:135-42. https://doi.org/10.1038/sj.ijo.0800555.

24. Ravaglia G, Forti P, Maioli F, Boschi F, Cicognani A, Gasbarrini G. Measurement of body fat in healthy elderly men: a comparison of methods. J Gerontol Ser A Biol Sci Med Sci. 1999;54. https://doi.org/10.1093/gerona/ 54.2.M70.

25. Pagotto V, Silveira EA. Applicability and agreement of different diagnostic criteria for sarcopenia estimation in the elderly. Arch Gerontol Geriatr. 2014; 59:288-94. https://doi.org/10.1016/j.archger.2014.05.009.

26. Silveira EA, Pagotto V, Barbosa LS, De OC, Pena GDG, Velasquez-Melendez G. Accuracy of BMl and waist circumference cut-off points to predict obesity in older adults. Cien Saude Colet. 2020;25:1073-82. https://doi.org/10.1590/ 1413-81232020253.13762018

27. Silveira EA, Vieira LL, de Souza JD. High prevalence of abdominal obesity among the elderly and its association with diabetes, hypertension and respiratory diseases. Cien Saude Colet. 2018;23:903-12. https://doi.org/10. 1590/1413-81232018233.01612016.

28. Bland JM, Altman DG. Comparing methods of measurement: why plotting difference against standard method is misleading. Lancet (London, Engl). 1995;346:1085-7 Available: http://www.ncbi.n/m.nih.gov/pubmed/7564793.

29. Lohman TG, Roche AF MR. Anthropometrics standardization reference manual. 1998.

30. Habicht J-P. Estandarizacion de métodos epidemiológicos cuantitativos sobre el terreno. Bol Sanit Panam. 1974:76:375-81.

31. Durnin JVGA, Womersley J. Body fat assessed from total body density and its estimation from skinfold thickness: measurements on 481 men and women aged from 16 to 72 years. Br J Nutr. 1974;32:77-97. https://doi.org/ 10.1079/BJN19740060.

32. Siri WE. Body composition from fluid spaces and density: analysis of methods. Nutrition. 1961;9:480-91 Available: http://www.ncbi.nlm.nih.gov/ pubmed/8286893.

33. Lin LI-K. A Concordance Correlation Coefficient to Evaluate Reproducibility. Biometrics. 1989;45:255. https://doi.org/10.2307/2532051.

34. da Silveira EA, Araújo CL, Gigante DP, Barros AJD, de Lima MS. Weight and height validation for diagnosis of adult nutritional status in southern Brazil. Cad Saude Publica. 2005:21:235-45. https://doi.org/10.1590/S0102$311 \times 2005000100026$ 
35. Hinkle DE, Wiersma W, Jurs SG. Applied statistics for the behavioral sciences. 5th ed. Boston: Hugton Miffin College Division; 2003

36. Stephen B, Swan P. Accuracy of estimating intra-abdominal fat in obese women. J Exerc Physiol. 1998;6:1-7 Available: https://asu.pure.elsevier.com/ en/publications/accuracy-of-estimating-intra-abdominal-fat-in-obesewomen.

37. Sillanpää E, Cheng S, Häkkinen K, Finni T, Walker S, Pesola A, et al. Body composition in 18- to 88-year-old adults-comparison of multifrequency bioimpedance and dual-energy X-ray absorptiometry. Obesity. 2014;22:1019. https://doi.org/10.1002/oby.20583.

38. Gába A, Kapuš O, Cuberek R, Botek M. Comparison of multi- and singlefrequency bioelectrical impedance analysis with dual-energy $X$-ray absorptiometry for assessment of body composition in post-menopausal women: effects of body mass index and accelerometer-determined physical activity. J Hum Nutr Diet. 2015;28:390-400. https://doi.org/10.1111/jhn. 12257.

39. Völgyi E, Tylavsky FA, Lyytikäinen $A$, Suominen $H$, Alén $M$, Cheng S. Assessing body composition with DXA and bioimpedance: effects of obesity, physical activity, and age. Obesity. 2008;16:700-5. https://doi.org/10. 1038/oby.2007.94

40. Rodrigues MN, Da SSC, Monteiro WD, De TV FP. Comparasion of body fat estimulation by electric impedance, skinfold thickness, and underwater weighing. Rev Bras Med do Esporte. 2001;7:125-31. https://doi.org/10.1590/ s0034-89102001000100007.

41. Both DR, Matheus SC, Behenck MS. Accuracy of different types of bioelectrical impedance to estimate body fat in men. Nutr Clin Diet Hosp. 2015;35:8-15. https://doi.org/10.12873/352both.

42. Machado RSP, Coelho MASC, Coelho KSC. Percentage of body fat among elderly: comparison between the methods of estimation by the mid-arm adipose area, tricipital skinfold thickness and tetrapolar bioimpedance analysis. Rev Bras Geriatr e Gerontol. 2010;13:17-27. https://doi.org/10.1590/ S1809-98232010000100003.

43. Hirani V, Mindell J. A comparison of measured height and demi-span equivalent height in the assessment of body mass index among people aged 65 years and over in England. Age Ageing. 2008;37:311-7. https://doi. org/10.1093/ageing/afm197.

\section{Publisher's Note}

Springer Nature remains neutral with regard to jurisdictional claims in published maps and institutional affiliations.

Ready to submit your research? Choose BMC and benefit from:

- fast, convenient online submission

- thorough peer review by experienced researchers in your field

- rapid publication on acceptance

- support for research data, including large and complex data types

- gold Open Access which fosters wider collaboration and increased citations

- maximum visibility for your research: over $100 \mathrm{M}$ website views per year

At $\mathrm{BMC}$, research is always in progress.

Learn more biomedcentral.com/submissions 